\title{
Performed Protocol Deviation Subcategory Code
}

National Cancer Institute

\section{Source}

National Cancer Institute. Performed Protocol Deviation Subcategory Code. NCI

Thesaurus. Code C95372.

A coded value specifying a subcategory of the performed protocol deviation. 